\title{
Preventing Homelessness: A Consumer Perspective
}

\author{
Kenneth R. Wireman
}

Published online: 5 June 2007

(C) Springer Science+Business Media, LLC 2007

Keywords Homelessness · Prevention · Consumer

The biggest problem is the way people look at you. The cold is something you get used to and you can always find food. But you cannot get past the looks, the quiet whispers, and the way it makes you feel. You begin to feel utterly hopeless after just a short time. Being homeless and having a mental illness makes things much worse. With this combination, you reach the bottom of the bottom. The other homeless people start looking at you differently. It is like being a subset of a subset. It makes everything that much harder. It is actually about as hopeless as you can get.

It is almost impossible to stay on a medication schedule while living on the streets. If you have delusions or paranoia, you have to counterbalance these symptoms with the notion that there really are folks out there in the middle of the night that will find you, beat you senseless, take what little money you have, and take any medications that you have. Being in a shelter is not much better. Sleeping is very difficult. Any symptom of mental illness is aggravated by being on the streets or in a shelter. Having a stable long-term place to live is what you need to work on your mental health recovery. Not just a place to stay or a program to count on, but a real place to call your own.

Kenneth R. Wireman is the Executive Director of Main Street Housing, Inc., which is a consumeroperated housing development corporation that has the capacity to provide housing for up to 46 individuals. He has extensive knowledge of Maryland's Public mental health system. In addition to having utilized mental health services, Mr. Wireman has worked in many capacities within the mental health field including serving as a case manager, licensed clinical therapist, emergency room psychiatric assessment clinician, and a county level mental health services administrator.

K. R. Wireman $(\bowtie)$

Main Street Housing, Inc., 1521 S. Edgewood Street Suite C, Baltimore, MD 21227, USA

e-mail: ken@onourownmd.org 
Getting from being homeless and unstable to having a home and mental health stability is like climbing to the top of Mount Everest. Even when others are available to help, there are so many setbacks and delays. It is really an uphill climb, so steep that you mostly sit at the bottom and stare up at the top, too hopeless to try to begin. It is very easy to give up entirely. The odds are stacked too high against you. Every step forward is paired with two steps back.

Irrespective of the odds, you have to keep trying. Every door that closes surely means that another door opens. You have to keep looking for that open door and finding the right path. However difficult, finding housing and getting the right mental health services is possible. If you remain diligent and seek the help that you need, you can succeed. Homeless people with mental illness do find housing and the services they need and they go on to live stable, productive lives in the community.

From a consumer perspective, the move toward preventing and ending homelessness is groundbreaking. People should not have to suffer the devastation and humiliation of homelessness before they get help. Prevention also makes economic sense. Although very important, helping a person who has become homeless takes much more time and effort than assisting folks with their hard work to circumvent homelessness. This is especially true for people transitioning from institutions into the community, where the right supports in conjunction with affordable housing must be a priority.

As we shift our energy and resources toward preventing homelessness, we must ensure that consumers are at the table and that their voices are heard. Having consumers involved in planning and implementation efforts are vital. Consumers, especially those who have experienced homelessness, know best what they want, what they need, and what will be helpful. It is important to make sure that programming is consumer-friendly and does what it is supposed to do. In taking steps toward these ends, the following key consumer-focused principles must be kept in mind as we work to prevent and end homelessness.

\section{The Goal of All Prevention Efforts Must be Safe, Stable, Affordable Housing in Mainstream Settings and High Quality Services in the Community}

From a consumer perspective, anything short of housing that has a landlord/tenant structure and is within the framework of mainstream housing options does not provide the essential foundation for a consumer's growth and recovery. Unfortunately, many options are provided by systems of care that do not address the critical need of having a home. Clearly, anything short of being out on the street can be seen as an improvement for a consumer, but it is a stopgap created by a system, rather than a real housing alternative that creates a true home environment. From a consumer perspective, the experience of homelessness is more subjective and is felt in settings as diverse as "being on the street" to living in a "residential service delivery bed." A psychiatric institution is in no way considered a home by consumers, as these settings do not provide the sense of comfort and security that a true home environment creates. 
Furthermore, the conditions imposed on consumers by some forms of housing result in consumers feeling like they are being tested or regularly scrutinized-and that this scrutiny has nothing to do with the requirements of maintaining housing in the community. These "below the surface" requirements take their toll on consumers, and only make it obvious to consumers that the kind of housing they are in is temporary or service-connected and not truly their own. It is paradoxical that in some programs, the sustainability of one's housing is inversely connected to the severity of their illness. Several years ago, I learned of an example where a consumer lost his service-linked housing because he became psychiatrically well. This kind of service-linked housing has a powerful presence in many mental health systems. Though it is most often an honest attempt at resolving the ongoing issue of the availability of affordable housing for people with mental illness, there is growing concern within the consumer movement that programmatically-based housing has a negative impact on consumers' efforts towards recovery.

Certainly, not all service linked housing arrangements are bad. A number of models that tie services to housing have been developed to help consumers return to the community after having been institutionalized. Unfortunately, some of this housing has the functional arrangement of "mini-institutions" in the community. Efforts must be made to change this kind of housing. Consumers need to work with these programs to help create a different foundation that can better promote consumer autonomy and "ownership" of their housing. In Maryland, much progress has been made in this area. Examples include organizations giving consumers keys to their housing, dropping old paternalistic rules, and developing leases for consumers to sign. Further, the Mental Hygiene Administration in Maryland has stopped funding any additional service-linked, programmaticallybased housing and has moved to funding the development of more supported and independent housing models.

This is not to say that the availability of mental health services is not important. Conversely, the right mental health services play a critical role in a consumer's recovery. But, ideally consumers' mental health service needs should be met regardless of where they live. It is vital that consumers have access to an adequate supply of high quality community-based services, including consumer-operated services, so that they have choices and a range of available service providers. It is not enough to simply provide housing or simply supply services. An orchestrated effort must be made to have each of these important community resources available to consumers in their work toward recovery. They need not be linked to each other, but rather they need to be available simultaneously to consumers as essential components of a person's move to wellness and recovery.

\section{Prevention Efforts Must Account for and Respond to the Unique Needs of Each Individual}

The homeless population is diverse and ever-changing, and each individual has his/ her own special circumstances. Overwhelmingly, consumers talk about the disconnect between what they need and what is available. Much of the assistance 
that is available does not meet people's direct needs. The systems of care that work to help those who are homeless and those with psychiatric disabilities use service delivery models that are more a function of the way these systems operate, rather than a function of addressing the true needs of individuals they are trying to serve.

A clear example of this is the kind of housing that is often made available to people with mental illness. Originally, during the major move toward deinstitutionalization, the mental health system developed group homes and congregate living arrangements. Although this has changed significantly, group homes still exist. I cannot think of many consumers, or anyone for that matter, who would actually prefer living with $8-16$ other people under the same roof. Shared housing where there are 3-4 individuals living together has been an improvement, yet if the housing is programmatically driven, you are rarely offered a lease or choice of roommates. Again, the development of independent housing where the individual has rights and responsibilities is where we need to go.

\section{The Prevention of Homelessness Must be Approached in the Context of an Individual's Growth, Recovery, and Empowerment}

What folks call us or what terms they use to describe our condition often sets the framework for how we are treated. Though used for uniformity in this article, "mental illness", is a medical model term that espouses the belief that recovery is the elimination of the illness and a return to "baseline functioning." It also focuses on what about us is sick, and often helps to portray the whole individual as sick or taking on the stereotypes that exist about people with mental illness. Focusing on a return to "baseline functioning" is very limiting and is often a hindrance to the ability of consumers and others to see positive aspects of a person's being and capacity.

Although many disagreements are presented within the consumer movement, there is overriding agreement that individuals' recovery is paramount and that systems of care should provide services and supports that facilitate individuals' recovery. A good definition of recovery from the consumer perspective is:

... recovery originated from the ideas, beliefs, and experiences of consumers and is centered on hope and the establishment of a meaningful life. Rather than a destination, recovery is seen as a journey that changes individuals' outlooks, how they perceive the world, and how they play a part in that world. It is a journey that transcends a medical, physical, or psychosocial model that defines mental illness. A primary concept of recovery is based on individuals taking charge of their own lives (Wireman and Hoffman 2004).

Issues of trauma also must be understood and addressed. Throughout the entire mental health system, as well as systems of care that address homelessness, there remains a serious lack of understanding about the need to see these issues in conjunction with the trauma of homelessness and the trauma experienced by individuals who are labeled with mental illness. Dr. Daniel Fisher, Executive Director of the National Empowerment Center, talks about mental illness from a 
consumer perspective which indicates that "many losses, conflicts, and traumas...can lead to varying degrees of emotional distress", (Fisher 2006). Further, such distress can be a reason for an individual to move away from a functioning role in society and cause serious decline in well-being. Such a definition and way of looking at homeless people with mental illness would allow for a healing approach that looks at the whole person and his/her situation. This is a much more dynamic approach than identifying the homeless person's mental health symptoms and explaining away their homeless condition as just one more symptom.

Addressing feelings of hopelessness is also critically important. Clarissa Netter, Executive Director of HOPE (Helping other People through Empowerment) in Baltimore, Maryland, reminds us that

even after sufficient resources are put forth to the individual, it does no good if that person is without hope! The installation of hope is the single most important aspect of any system's attempt to help. We have to realize that the individual is seeing things as impossible. Not only is hope fundamental to a consumer's recovery, but it is essential to make the effort it takes to get out of the homeless condition"' (C. Netter, personal communication, December 14, 2006).

The shift from giving relief to folks who are already homeless to helping prevent homelessness is a positive, recovery-oriented, consumer-friendly approach. In terms of prevention, the idea is to keep people where they currently reside. Ideally, this living arrangement is the consumer's choice, and will sustain the individual in his/ her current optimal living arrangement.

\section{Creating Expectations Helps People Reach Their Potential}

In all of our lives, the things truly worth attaining and cherishing come through challenge, adversity, personal struggle, and growth. This holds true for consumers as well. Consumers regularly find that the systems which provide them assistance expect very little of them and, as a result, they come to expect less of themselves. We must walk an uncomfortable tightrope-on one side there is a true lack of adequate resources, and on the other is an overwhelming tendency to enable rather than empower the individual in his/her struggle. Although progress can be made, consumers report that anything given for free without effort and commitment on the consumer's part can be relatively worthless compared to the consumer making an honest, hard fought effort toward recovery.

\section{Efforts to Prevent Homelessness Must not Forget or Blame Those who Remain Homeless}

It would be wonderful if a community could reduce its rate of homelessness by $50 \%$, but we need to remember that this does not mean anything to the folks who are 
still homeless, except perhaps that the amount of resources available to help them might be less, because there has been a reduction in the overall problem.

As we work to end homelessness, an inadvertent consequence might be the possibility that those who remain homeless after many resources are offered will somehow be blamed for their homelessness. We cannot look at the people who remain homeless after the effort to end homelessness and believe that these folks are homeless out of their own choice, or are to blame for their condition.

\section{Consumer Involvement Must Increase as the Move toward Homelessness Prevention Unfolds}

It is not enough to simply ask for consumer input after making efforts to develop a system of care to prevent homelessness. Consumers need to be at the planning table to help conceptualize these efforts. They need to have a say in the way things are thought through, designed, and accomplished. Very seldom in the business world is anything developed without learning first how the public will respond. In the business world, dollars are at stake. In the homeless world, lives are at stake. We can not move forward in developing something that should help consumers without seeing if consumers want to utilize it first.

In Maryland, the consumer movement looked at housing issues for consumers, and came to a very important conclusion. We concluded that consumer involvement regarding housing did not only mean sitting in policy development meetings, chairing or attending committees, advocating for more affordable housing, and meeting with stakeholders to discuss and influence policies and procedures. It meant we needed to actually develop the kinds of housing consumers say they want. We needed to show by example that the kind of independent housing that consumers want is possible to develop. We are doing just that.

Main Street Housing, Inc. is a consumer-operated housing development organization that develops quality, safe, affordable, and independent housing for individuals with psychiatric disabilities. It is a subsidiary of On Our Own of Maryland, Inc., the statewide consumer-operated advocacy and education organization in Maryland. Encompassed within the mission is a broader goal which includes exposing individuals, communities, and systems of care to actual evidence that consumers can and do become meaningful members of society in a significant recovery-oriented way. Through this program, consumers have purchased, rehabilitated, and rented to fellow consumers approximately 2 million dollars worth of rental property over the past 5 years. This is not an easy task, and for a consumeroperated organization to make successful strides in this arena is concrete evidence that affordable housing for consumers can and should be developed.

Main Street Housing, Inc. uses a "housing only" model, in which consumers are tenants in the community. An individual applicant needs to show evidence of disability to be a successful candidate for tenancy, but all other requirements for tenancy are no different than any other rental unit in the community. The program has no mental health service requirements to acquire or maintain a unit, but a tenant 
must follow rigorous lease-based requirements to remain in good standing. The lease is extensive in nature, yet upon close examination, the expectations fall into three simple "rules for good tenancy" - pay the rent on time, keep your unit clean and safe, and be a good neighbor. These expectations are no different than for anyone who rents a home in the community.

We have found that by becoming a tenant within the community, consumers assume a role that is outside the traditional role of mental health patients. This brings about a dynamic change in an individual's self-perception and also has the effect of forcing entire systems of care to see and treat consumers in a new and different way. This is the essence of systems change-pushing the status quo in a way that brings about change in the entire system and forcing the players within that system to think and act differently. Main Street Housing, Inc. is accomplishing just that in the state of Maryland.

Main Street Housing tenants have a real stake in their tenancy. They know the three basic components of tenancy are their own responsibility and that they are ultimately responsible for their continued tenancy. Such an earned status brings about a different, more fulfilling concept of self: one in which there is a distinct, responsible role in society and the expectations are no less and no different from anyone else's in the community. It is a role that helps the individual identify him/ herself as someone other than a "mental patient," the "crazy" person in the group home, or the "homeless guy" on the street corner. Such an environment creates an atmosphere that espouses one's inalienable right to struggle for and reach one's own achievements. And then to look at the rest of life's challenges and hear an internal voice that says, "I can do this! I can expect more from myself, and begin to set the bar higher." This is the very essence of recovery.

In one community where Main Street Housing has properties, over $80 \%$ of the tenants are significantly employed within the community. In several other communities, consumers are living with their spouse or children. One consumer lives in a unit, and has made it a home for herself and her four children. Such roles within the community take the person from a self-identified role as mental patient to a true member of society, an important member of a family, and part of the fabric of his/her community.

We need to ensure that as we work to shift systems of care toward ending homelessness that we support each individual's right to achievement and hope for the future. It is imperative that we change the circumstances of society so that people have the opportunity to better themselves and take on meaningful roles within their communities. People must have the chance to embrace their own accomplishments, however large or small, and stand with pride: to see themselves as something more than "the crazy person wandering the streets," to struggle, fight, and overcome the obstacles that are in their way. It is what we are all here for: to challenge ourselves, to meet life's obstacles, to reach our goals, and to stand with pride as a member of the community. 


\section{References}

Fisher, D. (2006). The President's New Freedom Commission on Mental Health: Achieving the promiseDeveloping a recovery oriented mental health system. Paper presented at On Our Own of Maryland's Statewide Leadership Summit: Voices of Transformation: Transforming Maryland's Public Mental health System, Ellicott City, Maryland.

Wireman, K. R., \& Hoffman, E. (2004). 30th Institute on Rehabilitation Issues 2004: Innovative methods for providing vocational rehabilitation services to individuals with psychiatric disabilities. Washington, DC: Rehabilitation Services Administration, US Department of Education. 